\title{
Etiological agents in Chronic Suppurative otitis Media
}

\author{
Khader KA ${ }^{1}$, Parihar $\mathbf{H}^{2}$, Mishra $\mathrm{RK}^{3}$ \\ ${ }^{1}$ Dr. Karnul Abdul Khader, Professor of ENT, ${ }^{2}$ Dr Harlal Parihar, Professor of Respiratory Medicine, ${ }^{3}$ Dr Rakesh Kumar \\ Mishra, Assistant Professor, Department of Radio diagnosis. All are affiliated with L N Medical College, Bhopal, MP, \\ India.
}

Address for correspondence: Dr Karnul Abdul Khader, Email: karnuladbulkhaderijmrr@gmail.com

\begin{abstract}
Introduction: Chronic suppurative otitis media is an important cause of preventable hearing loss, particularly in the developing world. It is characterized by recurrent discharge from middle ear cavity through perforated tympanic membrane. Prevalence varies from eastern world when compare with western hemisphere. Most of the organisms are resistant to various antibiotics. We have conducted this study to identify etiological organism. Methods: This study was a case control analysis study conducted in tertiary care teaching hospital of Central India after taking permission from Institutional Research board [IRB]. Total duration of study was 2 years. 216 patient's patients who came to OPD or admitted in hospital for chronic ear discharge \& full fill inclusion criteria have been included in study. Results: Out of 216 patients $119(55 \%)$ were male \& $97(45 \%)$ were female. Staphylococcus $(25 \%, \mathrm{n}=55)$ \& Pseudomonas $(26 \%, \mathrm{n}=56)$ together were two most common organisms comprised nearly fifty percent of total patients. Nearly $30 \%$ of culture did not reveal any growth. Candida was most common fungus on culture comprised nearly $7 \%$ of total population. Conclusion: Sensitivity pattern varies with geographical areas but most of the organisms are sensitive with ciprofloxacin ear drops. It is consider first line of drugs for CSOM.
\end{abstract}

Key words: Chronic suppurative otitis media, Etiology, Culture \& sensitivity pattern

\section{Introduction}

Chronic suppurative otitis media (CSOM) is the result of an initial episode of acute otitis media and is characterized by a persistent discharge from the middle ear through a tympanic perforation. It is an important cause of preventable hearing loss, particularly in the developing world [1].

Prevalence surveys, which vary widely in disease definition, sampling methods, and methodologic quality, show that the global burden of illness from CSOM involves 65-330 million individuals with draining ears, $60 \%$ of whom (39-200 million) suffer from significant hearing impairment. CSOM accounts for 28,000 deaths and a disease burden of over 2 million DALYs. Over $90 \%$ of the burden is borne by countries in the South-east Asia and Western Pacific regions, Africa, and several ethnic minorities in the Pacific rim. CSOM is uncommon in the Americas, Europe, the Middle East, and Australia [1]. A systematic review has shown that chronic suppurative otitis media incidence rate is $4.76 \%$ i.e.

Manuscript received: $24^{\text {th }}$ June 2014

Reviewed: $07^{\text {th }}$ July 2014

Author Corrected: $14^{\text {th }}$ July 2014

Accepted for Publication: $10^{\text {th }}$ Aug2014
31 million cases, with $22.6 \%$ of cases occurring annually in under-fives. CSOM is also responsible for 30.81/ thousand hearing loss each year [2]. Each year 21 thousand people die due to complications of OM [2].

Frequent upper respiratory tract infection, Low socioeconomic status, Poor hygiene, undernutrition are associated with CSOM [3-5]. Some studies have shown relationship between maternal education, bathing habits, ear cleaning habits [6]. Disease prevalence was also found higher among the dwellers of kachha house [6].

High prevalence of CSOM is associated with inadequate breast feeding, poor hygine, overcrowding, passive smoking, recurrent Respiratory tract infection, impaired immune response, colonization of nasopharynx by pathogenic organism and Non availability of health care facilities [1]. Recurrent Chronic suppurative otitis media is most common reason responsible for hearing loss $[1,7]$. Cholesteatoma, mastoid abscess, labyrinthitis, facial nerve palsy, benzold's abscess, brain abscess, sinus abscess, meningitis are other known complication of CSOM [8-11]. 
Chronic suppurative otitis media is chronic discharging ear is one with a perforated tympanic membrane and persistent drainage from the middle ear. Unlike otitis media with effusion which is common in the West and associated with serous discharge instead of purulent $[12,13]$.

Management of CSOM is daily ear dressing till dry ear is achieved with antibiotic drops $[14,15]$. In complicated cases mastoidectomy should be done [15].

Bacteriological profile of Acute suppurative otitis media is different than CSOM. Acute suppurative otitis media is caused by respiratory organism like Streptococcus pneumoniae, Staphylococcus aureus, Haemophilus influenzae and Micrococcus catarrhalis. These organisms are commonly present in nasopharynx \& can reach to middle ear during respiratory tract infections [1].

Chronic suppurative otitis media is commonly caused by aerobic (e.g. Pseudomonas aeruginosa, Escherichia coli, S. aureus, Streptococcus pyogenes, Proteus mirabilis, Klebsiella species) or anaerobic (e.g. Bacteroides, Peptostreptococcus, Proprionibacterium) [16, 17]. These organisms are commonly present in external ear canal. They can reach to middle ear cavity in tropical conditions like humidity, high temperature, trauma, laceration in presence of middle ear perforated canal $[1,17]$.

Among these bacteria, $P$. aeruginosa has been particularly blamed for the deep-seated and progressive destruction of middle ear and mastoid structures through its toxins and Enzymes [1].

Ear discharge is most common problem for Ear, Nose \& throat outpatient department visit. CSOM is major burden in society. Identification of etiological organism is not only important for diagnosis purpose but also aid in advising patients regarding prognosis \& complications. Few aetiological agents are more common in healthcare settings; the healthcare institutions can take appropriate sterilization practices to prevent further spread.

Therefore we have conducted this study to identify etiological agent (Bacteria, Fungus) and risk factor for CSOM.

\section{Methods}

\section{Study design}

This study was a case control analysis study conducted in tertiary care teaching hospital of Central India after taking permission from Institutional Research board
[IRB]. Total duration of study was 2 years. All the patients who came to OPD or admitted in Hospital for chronic ear discharge \& full fill inclusion criteria have been included in study.

\section{Patients}

All in patients who presented to the ENT Department during the study period and had ear discharge of more than six weeks duration despite out-patient treatment were included in the study.

\section{Exclusion criteria}

1. Acute suppurative otitis media (Ear discharge less than 6 weeks)

2. Serous otitis media

3. Otitis externa with CSOM

4. Terminally ill patients

5. Evidences of septicaemia in patients

6. Patients not willing to participate in study

7. Immunocompromised patients

\section{Collection of Samples}

Samples were collected from patients before administering any antibiotics drops. History was obtained about any recent drug administration in the ears.

Specimens for pus culture were collected, under illumination, by swabbing the discharging ears with a sterile cotton swab and sent to the microbiology laboratory of the hospital immedietely.

Samples collected were inoculated in nutrient agar and Mackonkey medium and incubated for 24 to $48 \mathrm{~h}$ at $37 \mathrm{C}$. On visible growth of bacterial colonies, microscopic and various chemical and enzymatic tests were conducted to identify the bacteria. Antibiotics sensitivity testing was done for commonly available drugs.

\section{Data Analysis}

All data collected were entered into the Statistical Package for Scientific Studies (SPSS) version 17.0 and standard deviations (SD), standard errors (SE), standard normal deviates (SND) and probability values were calculated.

\section{Results}

During study period 296 patients came with history of ear discharge. 216 patients were full filled inclusion criteria and included for further analysis.

Out of 216 patients 119 (55\%) were male \& 97 (45\%) were female (Fig 1). Most of the patients (78\%) belong 


\section{Research Article}

to lower socioeconomic strata as per modified Prasad classification. Most of the patients were young (below 30 years of the age). Children below 10 years comprised a significant proportion (17\%). (Fig 2)

Table 3 is showing culture pattern after sterile ear swab sampling. We have excluded patients who have taken medication in form of ear drops before sampling. Staphylococcus $(25 \%, \mathrm{n}=55) \&$ Pseudomonas $(26 \%, \mathrm{n}=$ 56) together were two most common organisms comprised nearly fifty percent of total patients. Nearly 30 $\%$ of culture did not reveal any growth. Candida was most common fungus on culture comprised nearly $7 \%$ of total population.

On statistical analysis there was no significant association between demographic factors \& CSOM. There was no significant association between age \& CSOM ( $p>0.5$ ). However CSOM was less common in females \& elderly age group.

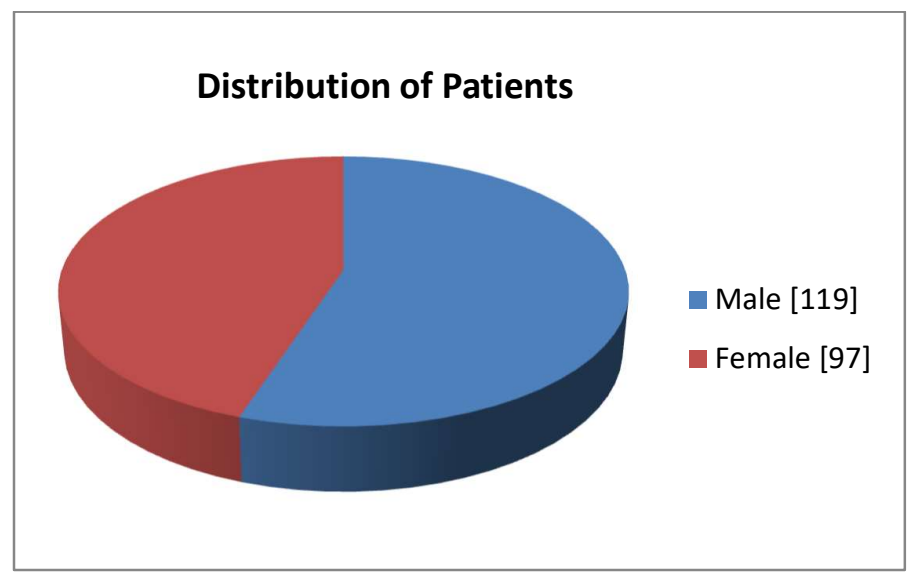

Fig 1: Pie chart showing male \& Female Distribution

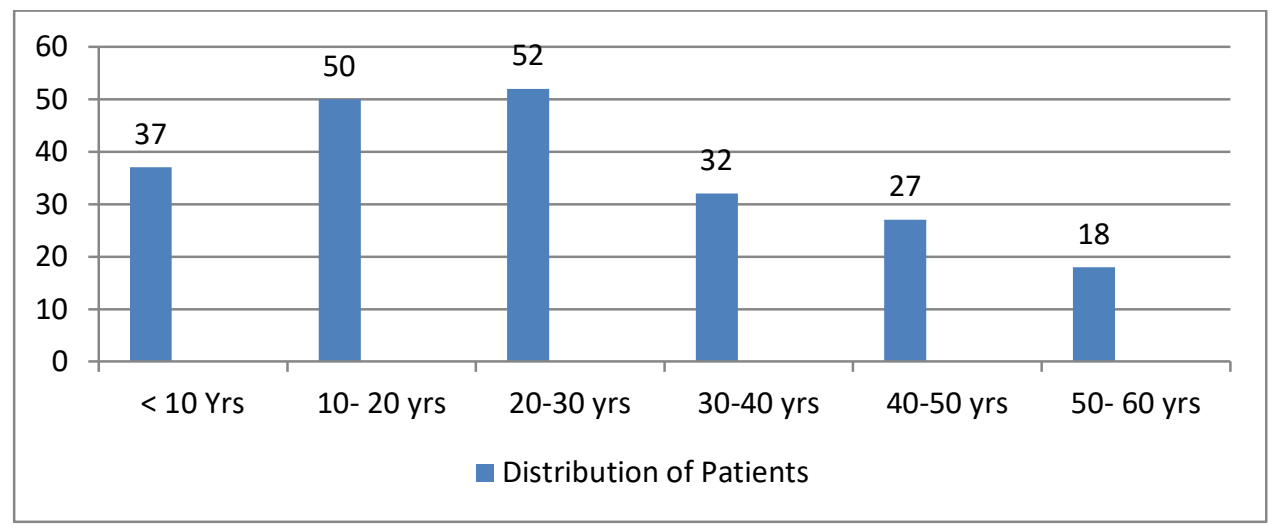

Fig 2: Distribution of patients in different age group

Table No 1: Culture growth of various organism

\begin{tabular}{|l|l|l|}
\hline Sr No & Organism growth & Number of patients \\
\hline 1 & Coliforms & 20 \\
\hline 2 & Staphylococcus & 55 \\
\hline 3 & Psedomonas & 54 \\
\hline 4 & Enterococcus & 8 \\
\hline 5 & Candida & 15 \\
\hline 6 & No growth & 64 \\
\hline
\end{tabular}




\section{Discussion}

Chronic suppurative otitis media is defined as recurrent ear discharge from ear from permanent perforation which does not heals spontaneously.

Demographic observation revealed male predominance with male to female ratio 1.25 : 1 . It was not statistically significant. Most of the other studies observed male predominance $[18,19]$. It may be due to skewed male to female ratio. Another explanation is males normally seek medical attention first than females.

Children below 10 years comprised almost one fourth of total culture positive patients. Predominance of CSOM is also observed in other studies [20,21]. Children are more prone because of malnutrition, recurrent upper respiratory tract infection $\&$ altered immune status.

In our study common organism includes Psedomonas, shaphylococcus, coloforms \& candida. Other studies from tropical area have observed pseudomonas \& staphylococcus together as most common organism [17, $18]$.

In our study these two organisms comprised nearly 50 percent of culture positive population. One more study from tropical countries has observed $44 \%$ culture positive staphylococcus \& $39 \%$ pseudomonas in their study. Together they comprised nearly $83 \%$ of total cases which is higher than what we have observed in our study [21].

Bacteriological pattern also varies with demographic area [22]. One of the African study has observed proteus as most common organism followed by pseudomonas \& staphylococcus [23].

In our study it was evident that nearly $20 \%$ of patients did not yield any organism. Prior antibiotics use before culture sample, improper technique $\&$ delayed sending of swab culture in slow resolving CSOM would be contributory factors.

In our study sensitivity pattern was accessed for ciprofloxacin, Gentamycin, tobramycin \& erythromycin. Almost $90 \%$ of organisms were sensitive for ciprofloxacin.

Most of the pseudomonas \& staphylococcus were sensitive for quinolones. Sensitivity pattern with other antibiotics were variable. Other studies have also shown good sensitivity pattern with quinolones [18, 24, 25, 26].
Ciprofloxacin drops can be considering first line drugs for most of CMOS cases. Most of the pseudomonas organisms with others are sensitive with ciprofloxacin. Now there are emergences of new bacteria which are resistant to quinolones from Asian countries [27].

\section{Conclusion}

Pseudomonas \& staphylococcus are two most common organism responsible for cronic suppurative otitis media. Sensitivity pattern varies with geographical areas but most of the organisms are sensitive with ciprofloxacin ear drops. They are consider first line of drugs for CSOM.

We have not observed any statistical significant association between age \& sex with CSOM but it is more common in children \& adolescents. Elderly population \& females are less affected.

\section{Funding: Nil}

Conflict of interest: Nil

Permission from IRB: Yes

\section{References}

1. Dr Jose Acuin, Philippines. Chronic suppurative otitis media Burden of Illness and Management Options. Available at: http://www.who.int/pbd/publications/Chronicsuppurativ eotitis_media.pdf cited on 2/10/2014.

2. Lorenzo Monasta, Luca Ronfani, Federico Marchetti, Marcella Montico, Liza Vecchi Brumatti, Alessandro Bavcar, Domenico Grasso, Chiara Barbiero, Giorgio Tamburlini. Burden of Disease Caused by Otitis Media: Systematic Review and Global Estimates. PLoS One. 2012; 7(4): e36226

3. Tos M. Sequelae of secretory otitis media and the relationship to chronic suppurative otitis media. Ann Otol Rhinol Laryngol. 1990; 99:18-9.

4. Daly KA, Hunter LL, Levine SC, et al. Relationships between otitis media sequelae and age. Laryngoscope 1998;108:1306-10.

5. Verhoeff M, Van der,V, Rovers MM, Sanders EA, Schilder AG; Chronic suppurative otitis media: A review. International Journal of Pediatric Otorhinolaryngology 2006;70:1-12.

6. Md. Mazharul Shaheen, Ahmed Raquib, Shaikh Muniruddin Ahmad. Chronic Suppurative Otitis Media 
and Its Association with Socio-Econonic Factors Among Rural Primary School Children of Bangladesh. Indian J Otolaryngol Head Neck Surg. Mar 2012; 64(1): 36-41.

7. Jensen RG, Koch A, Homøe P. The risk of hearing loss in a population with a high prevalence of chronic suppurative otitis media. Int J Pediatr Otorhinolaryngol. 2013 Sep;77(9):1530-5.

8. Yorgancilar $\mathrm{E}^{1}$, Yildirim M, Gun R, Bakir S, Tekin R, Gocmez C, Meric F, Topcu I. Complications of chronic suppurative otitis media: a retrospective review. Eur Arch Otorhinolaryngol. 2013 Jan;270(1):69-76.

9. S H C, M M K, Handi P, Khavasi P, Doddmani SS, Riyas M. To Study the Level of Awareness About Complications of Chronic Suppurative Otitis Media (CSOM) in CSOM Patients. J Clin Diagn Res. 2014 Feb;8(2):59-61

10. Dubey SP, Larawin V. Complications of chronic suppurative otitis media and their management. Laryngoscope. 2007 Feb;117(2):264-7.

11. Saha SN, Chandra S, Srivastava A, Ghosh A. An unusual complication of CSOM - Lateral sinus thrombosis with lung abscess: A clinicoradiological study. Indian J Otolaryngol Head Neck Surg. 2007 Dec;59(4):349-52.

12. Olusanya BO, Okolo AA, Ijaduola GTA.The hearing profile of Nigerian school children. Int $\mathrm{J}$ Paediatr Otorhinolaryngol 2000, 55(3): 173-9.

13. Mcpherson B, Holborow CA. A study of deafness in West Africa: the Gambian Hearing Health Project. Int. J Pediatr Otorhinolaryngol 1985, 10:115-135.

14. Renukananda GS, U P S, George NM. Topical vs Combination Ciprofloxacin in the Management of Discharging Chronic Suppurative Otitis Media. J Clin Diagn Res. 2014 Jun;8(6):KC01-4.

15. Orji F. A survey of the burden of management of chronic suppurative otitis media in a developing country. Ann Med Health Sci Res. 2013 Oct;3(4):598-601.

16. Brobby GW, Zadik P. Bacteriology of otitis media in Ghana. Tropical Doctor, 1987, 17:91-92.
17. Brook I, Frazier E. Microbial dynamics of persistent purulent otitis media in children. J Pediatrics, 1996, 128(2): 237-240.

18. Deb T, Ray D. A study of the bacteriological profile of chronic suppurative otitis media in agartala. Indian $\mathrm{J}$ Otolaryngol Head Neck Surg. 2012 Dec;64(4):326-9.

19. Dayasena RP, Dayasiri MBKC, Jayasuriya C, Perera DSC; Aetiological agents in chronic suppurative otitis media in Sri Lanka. AMJ 2011, 4, 2, 101-4. Doi: http://dx.doi.org/10.4066/AMJ.2011.549.

20. Biagio $\mathrm{L}^{1}$, Swanepoel DW, Laurent C, Lundberg T. Paediatric otitis media at a primary healthcare clinic in South Africa. S Afr Med J. 2014 May 12;104(6):431-5. doi: 10.7196/samj.7534.

21. Hallbauer UM, Atkins MD, Tiedt NJ, Butler IR, Pieters M, Elliott E, Joubert G, Seedat RY. Comorbidities in children presenting with chronic suppurative otitis media--a South African study. J Trop Pediatr. 2014 Jun;60(3):198-202. doi: 10.1093/tropej/fmt107. Epub 2014 Jan 8.

22. Ahmed B, Hydri AS, Afridi AAK, Ejaz A, Farooq S, Zaidi SK. Microbiology of ear discharge in Quetta.J Coll Physicians Surg Pak Sep 2005; 15(9):5834.

23. Aduda DS, Macharia IM, Mugwe P, Oburra H, Farragher B, Brabin B, Mackenzie I. Bacteriology of chronic suppurative otitis media (CSOM) in children in Garissa district, Kenya: a point prevalence study. Int J Pediatr Otorhinolaryngol. 2013 Jul;77(7):1107-11. doi: 10.1016/j.ijporl.2013.04.011.

24. Renukananda GS, U P S, George NM. Topical vs Combination Ciprofloxacin in the Management of Discharging Chronic Suppurative Otitis Media. J Clin Diagn Res. 2014 Jun;8(6):KC01-4. doi: 10.7860/JCDR/2014/8038.4421.

25. van Hasselt $P$, van Kregten E. Treatment of chronic suppurative otitis media with ofloxacin in hydroxypropyl methylcellulose eardrops: a clinical/bacteriological study in a rural area of Malawi. Int J Pediatr Otorhinolaryngol. 2002 Mar 15;63(1):49-56.

26. Alper CM, Dohar JE, Gulhan M, Ozunlu A, BaggerSjobak D, Hebda PA, Swarts JD. Treatment of chronic suppurative otitis media with topical tobramycin and 
dexamethasone. Arch Otolaryngol Head Neck Surg. 2000 Feb;126(2):165-73
27. Jang CH, Park SY . Emergence of ciprofloxacinresistant pseudomonas in chronic suppurative otitis media. Clin Otolaryngol Allied Sci 2004.29(4):321-323

\section{How to cite this article?}

Khader KA, Parihar H, Mishra RK. Etiological agents in Chronic Suppurative otitis Media. Int J Med Res Rev 2014;2(5):463- 468. doi:10.17511/ijmrr.2014.i05.10 